\title{
The role of antibodies to mutated citrulinated vimentin (anti-MCV) in juvenile idiopathic arthritis patients
}

\author{
L Lamot*1, A Tesija Kuna², M Zirovic ${ }^{2}$, AM Simundic ${ }^{2}$, E Topic ${ }^{2}$ and \\ M Harjacek $^{1}$
}

\author{
Address: ${ }^{1}$ Children's Hospital Zagreb, Zagreb, Croatia and ${ }^{2}$ Clinical Institute of Chemistry School of Medicine University of Zagreb. Sestre \\ milosrdnice University Hospital, Zagreb, Croatia \\ * Corresponding author
}

from 15th Paediatric Rheumatology European Society (PreS) Congress

London, UK. 14-17 September 2008

Published: 15 September 2008

Pediatric Rheumatology 2008, 6(Suppl I):P69 doi:I0.II86/I546-0096-6-SI-P69

This abstract is available from: http://www.ped-rheum.com/content/6/SI/P69

(c) 2008 Lamot et al; licensee BioMed Central Ltd.

\section{Background}

Anti-MCV antibodies ( $\mathrm{Ab}$ ) have high sensitivity and prognostic value in patients with RA. We attempt to correlate positive anti-MCV Ab in different subtypes of JIA patients with six core outcome variables.

\section{Patients and methods}

Anti-MCV Ab and Anti-CCP Ab were tested by ELISA (Orgentec, Germany) in sera from 57 JIA, and 14 control patients (12 patients with SLE, 1 with MCTD and 1 with synovial cyst). (16 boys, 41 girls), The mean age was 11,2 years (range 2,5-18,0), and mean disease duration was 3 , 4 years $(S D \pm 2.9)$. Cut off value $\geq 20 \mathrm{U} / \mathrm{mL}$ was considered positive.

\section{Results}

Positive anti-MCV Ab were detected in only 3/58 (5,2\%) JIA patients, and were significantly elevated in two RF positive polyartritis patients, and slightly elevated in 1/19 (5,3\%) patients with enthesitis-related arthritis (ErA). Among all patients, anti-CCP Ab were positive only in one anti-MCV positive polyarticular JIA patient. Anti-MCV and RF positivity correlated statistically $(\mathrm{r}=0,504, \mathrm{P}=$ 0,028 ) in ErA, while no association between anti-MCV Ab and six core outcome variables was observed in this, or other JIA subtypes. Unexpectedly, anti-MCV was detected in $3 / 12(25 \%)$ SLE patients (2 low positive and 1 significantly positive), and in 1 patient with MCTD. All of these patients were both RF and anti-CCP negative.

\section{Conclusion}

In contrast to RA, anti-MCV antibodies are not specific for JIA. However, within JIA patients, significantly elevated levels are almost exclusively found in two RF positive, polyarticular patients.

\section{References}

I. Innala L, Kokkonen H, Eriksson C, Jidell E, Berglin E, Dahlqvst SR: Antibodies Against Mutated Citrullinated Vimentin Are a Better Predictor of Disease Activity at 24 Months in Early Rheumatoid Arthritis Than Antibodies Against Cyclic Citrullinated Peptides. J Rheumatol in press. 2008 Apr I

2. Mathsson L, Mullazehi M, Wick MC, Sjöberg O, et al.: Antibodies against citrullinated vimentin in rheumatoid arthritis: higher sensitivity and extended prognostic value concerning future radiographic progression as compared with antibodies against cyclic citrullinated peptides. Arthritis Rheum 2008, 58(1):36-45. 